\title{
THE UPPER BOUNDS FOR MULTIPLICATIVE SUM ZAGREB INDEX OF SOME GRAPH OPERATIONS
}

\author{
YAsar NaCARoglu and A. Dilek MAden
}

Abstract. Let $\mathrm{G}$ be a simple graph with vertex set $\mathrm{V}(\mathrm{G})$ and edge set $\mathrm{E}(\mathrm{G})$. In [7], Eliasi et al. introduced the multiplicative sum Zagreb index of a graph $\mathrm{G}$ which is denoted by $\Pi_{1}^{*}(G)$ and is defined by

$$
\Pi_{1}^{*}(G)=\prod_{u v \in V(G)}\left(d_{G}(u)+d_{G}(v)\right) .
$$

In this paper, we present some upper bounds for the multiplicative sum Zagreb indices of the join, rooted product, corona product, tensor product, Cartesian product, strong product, hierarchical product, lexicographic product of graphs.

Mathematics subject classification (2010): 05C35, 05C76, 05 C07.

Keywords and phrases: Zagreb indices, multiplicative sum Zagreb index, join, rooted product, corona product, tensor product, cartesian product, strong product, hierarchical product, lexicographic product.

\section{REFERENCES}

[1] M. Arezoomand, B. TAeri, Zagreb indices of the generalized Hierarhical product of graphs, MATCH Commun. Math. Comput. Chem., 69, (2013) 131-140.

[2] M. Azari And A. IRAnmanesh, Chemical Graphs constructed from Rooted product and their Zagreb indices, MATCH Commun. Math.Comput.Chem., 70, (2013) 901-909.

[3] M. AZARI, Sharp lower bounds on the Narumi-Katayama index of graph operations, Appl. Math. and Comput., 239, (2014) 409-421.

[4] M. AZARI AND A. IRANMANESH, Some inequalities for the multiplicative sum zagreb index of graph operations, J. of Math. Ineq., 9, (3) (2015) 727-738.

[5] J. A. Bondy And U. S. R Murty, Graph Theory with Applications, Macmillian Co., (1976) New York.

[6] K. C. Das, A. Yurttas, M. Togan, A. S. Cevik and I. N. Cangul, The multiplicative Zagreb indices of graph operations, J. Inequal. Appl., 2013:90 (2013).

[7] M. Eliasi, A. Iranmanesh, I. Gutman, Multiplicative versions of first Zagreb index, MATCH Commun. Math. Comput. Chem., 68, (2012) 217-230.

[8] I. Gutman, Multiplicative Zagreb indices of trees, Bull. Int. Math. Virt. Inst, 239, (2011) 13-19.

[9] I. GutMAn AND N. TRInAJstić, Graph theory and molecular orbitals, Total $\pi$ electron energy ofalternant hydrocarbons, Chem. Phys. Lett., 17, (1972), 535-538.

[10] W. ImRICH, S. KlaVŽAR, Product Graphs: Structure and Recognition, Wiley, New York, USA, 2000.

[11] J. LIU, Q. ZhANG, Sharp upper bounds on multiplicative Zagreb indices, MATCH Commun. Math.Comput. Chem., 68, (2012) 231-240.

[12] S. Nikolić, G. Kovaćević, A. Milićević and N. Trinajstić, The Zagreb indices 30 years after, Croat. Chem. Acta., 76, (2003), 113-124.

[13] R. Todeschini, V. Consonni, Handbook of Molecular Descriptors, Wiley-VCH, Weinheim, 2000.

[14] R. Todeschini, V. Consonni, New local vertex invariants and molecular descriptors based on functions of the vertex degrees, MATCH Commun. Math. Comput. Chem., 64(2010) 359-372.

[15] N. TrinajSTIĈ, Chemical Graph Theory, CRC press, Boca Raton, 1992 
[16] K. XU, K. C. DAS, Trees, unicyclic and bicyclic graphs extremal with respect to multiplicative sum Zagreb index, MATCH Commun. Math.Comput. Chem., 68, (1) (2012) 257-272.

[17] K. XU, H. HUA, A unified approach to extremal multiplicative Zagreb indices for trees, unicyclic and bicyclic graphs, MATCH Commun. Math.Comput.Chem., 68, (2012) 241-256.

[18] Y. N. YeH AND I. Gutman, On the sum of all distances in composite graphs, Discrete Math., 135, (1-3) (1994), 359-365.

[19] B. Zhou And I. Gutman, Further properties of Zagreb indices, MATCH Commun. Math. Comput. Chem., 54, (2005), 233-239. 